\title{
Can body mass index identify cardiac autonomic dysfunction in women who are apparently healthy?
}

\section{Fabiano Henrique Rodrigues Soares, Alexandra Braga Furstenberger, Layssa Carolinne de Sousa Carvalho, Melissa Yolanda Soares Melo, Josivan Gomes Lima \& Maria Bernardete Cordeiro de Sousa}

To cite this article: Fabiano Henrique Rodrigues Soares, Alexandra Braga Furstenberger, Layssa Carolinne de Sousa Carvalho, Melissa Yolanda Soares Melo, Josivan Gomes Lima \& Maria Bernardete Cordeiro de Sousa (2019): Can body mass index identify cardiac autonomic dysfunction in women who are apparently healthy?, Women \& Health, DOI: 10.1080/03630242.2019.1613472

To link to this article: https://doi.org/10.1080/03630242.2019.1613472

曲 Published online: 16 May 2019.

Submit your article to this journal $[\pi$

View Crossmark data $\asymp$ 


\title{
Can body mass index identify cardiac autonomic dysfunction in women who are apparently healthy?
}

\author{
Fabiano Henrique Rodrigues Soares MSc. (1) ${ }^{a}$, Alexandra Braga Furstenberger ${ }^{a}$, \\ Layssa Carolinne de Sousa Carvalho a, Melissa Yolanda Soares Meloa, \\ Josivan Gomes Limaa, and Maria Bernardete Cordeiro de Sousa PhD ${ }^{\mathrm{b}}$
}

aHealth Science Center, Federal University of Rio Grande do Norte, Natal, Rio Grande do Norte, Brazil; ${ }^{\text {bBrain }}$ Institute, Federal University of Rio Grande do Norte, Natal, Rio Grande do Norte, Brazil

\begin{abstract}
We investigated the extent to which obesity could identify autonomic dysfunction of heart control in a cross-sectional study with 65 women (aged 18-45 years), categorized as eutrophic, overweight or obese. We collected anthropometric measures and measures of heart rate variability (HRV) between March 2015 and March 2017. Low frequency in normalized units $\left(\mathrm{LF}_{(\mathrm{nu})}\right)$ over 46 was considered a marker of autonomic imbalance and high frequency in normalized units $\left(\mathrm{HF}_{(\mathrm{nu})}\right)$ below 38 a marker of depressed vagal modulation. Overweight (mean difference $\mathrm{M} \Delta \mathrm{HF}_{(\mathrm{nu})}=-13.11$ [95\% confidence interval $(\mathrm{Cl})$ of difference, $-25.88,-0.34]$, Hedges's $g=0.65$, common language effect size $(C L)=68.1 \%)$ and obese $\left(M \Delta \mathrm{HF}_{(\mathrm{nu})}=-21.22[95 \%\right.$ $\mathrm{Cl},-31.89,-10.55]$, Hedges's $g=1.17, \mathrm{CL}=79.2 \%)$ women presented depressed vagal modulation compared to eutrophic women. Autonomic imbalance increased as body mass index increased (eutrophic-to-overweight $\mathrm{M} \Delta \mathrm{LF}_{(\mathrm{nu})}=13.06[95 \% \mathrm{Cl}, 1.65,24.47]$, $g=0.65, \mathrm{CL}=67.9 \%$, and overweight-to-obese $\mathrm{M} \Delta \mathrm{LF}_{(\mathrm{nu})}=21.07$ [95\% Cl, 10.32, 31.82], $g=1.15, \mathrm{CL} 78.9 \%)$. The odds ratio for depressed $\mathrm{HF}_{(\mathrm{nu})}$ among overweight women was $2.36(95 \% \mathrm{Cl} 0.77,7.29)$ and 2.18 among obese women $(95 \% \mathrm{Cl} 0.79,5.99)$, as well as $9.17(95 \% \mathrm{Cl} 2.62$, $32.04)$ and 17.39 for increased $\mathrm{LF}_{(\mathrm{nu})}(95 \% \mathrm{Cl} 2.13,141.76)$, respectively. The parasympathetic activity is diminished and autonomic imbalance of the cardiac control increased with increasing BMI categories.
\end{abstract}

\section{ARTICLE HISTORY}

Received 4 November 2018

Revised 9 April 2019

Accepted 11 April 2019

\section{KEYWORDS}

Body mass index (BMI); cardiac dysfunction; HRV; obesity

\section{Introduction}

Overweight and obesity represent a major public health concern with a global scope, heterogeneous patterns and wide-ranging impacts (Lee et al. 2017). Prevalence of obesity has increased over recent decades, doubling in more than 70 countries with an estimated 600 million obese adults worldwide (The GBD Obesity Collaborators 2017). Obesity remains a well-established risk factor for numerous chronic diseases and disabilities (Chang, Alley, and Dowd 2017) and contributed to over 4 million deaths in 2015, with 2.7 million of them being related to cardiovascular disease. Such a burden of obesityrelated diseases is even higher among women, as female obesity and severe obesity

CONTACT Fabiano Henrique Rodrigues Soares fsfitness@hotmail.com $\mathrm{Q}$ Health Science Center, Federal University of Rio Grande do Norte, Av. Nascimento de Castro, 2155 - Morro Branco, Natal, RN 59056-450, Brazil

Color versions of one or more of the figures in the article can be found online at www.tandfonline.com/wwah. 
prevalence are higher than in men for all age ranges, surpassing $21 \%$ and $9 \%$, respectively (The GBD Obesity Collaborators 2017).

Cardiac autonomic modulation has been reliably assessed through markers of sympathetic/parasympathetic activity, represented by measures of heart rate variability (HRV). It constitutes an easy to apply a non-invasive method to assess the autonomic modulation of the sinus node. Imbalances in autonomic control of the heart (i.e., depressed parasympathetic activity) represent a significant risk factor for cardiovascular and metabolic disorders (Malik 1996; Yoo et al. 2016).

Anthropometric measures and central adipose distribution, such as body mass index (BMI) or waist-to-hip ratio (WHR), also represent reliable indicators of cardiometabolic risk. The assessment of adipose tissue quantity and distribution holds the power to indicate the presence and the degree of metabolic disorders associated with systemic inflammation, and ultimately cardiac events (Nishida, Ko, and Kumanyika 2010).

Reciprocal interconnections of central autonomic and metabolic control networks in humans further highlight the clinical relevance of assessing HRV (Wheat and Larkin 2010). In this context, the development of fast, simple and reliable initial screening and early diagnostic techniques for clinicians is paramount. Therefore, we aimed to i) compare measures of HRV across BMI ranges; and ii) examine to what extent standard anthropometric measures are related to cardiac autonomic dysfunction. We hypothesized (following the literature) that anthropometric measures would correlate with HRV variables and that BMI would be associated with asymptomatic cardiac autonomic dysfunction.

\section{Methods}

\section{Study participants}

This was a cross-sectional study with 65 apparently healthy, sedentary women $(<150$ min/week of moderate-vigorous physical activity), aged 18-45 years old, without a history of metabolic or cardiac complications. The sample size was estimated a priori in 61 individuals assuring a critical Pearson's coefficient $(r=0.256)$, onetailed $\alpha=0.05$ and statistical power $=0.95$ (Faul et al. 2009) for all HRV variables. A convenience sample was constituted by candidates from the general population who responded to advertisements publicized at health centers and at the Federal University of Rio Grande do Norte (UFRN) University Hospital. They were informed about study's benefits and possible risks, and needed to meet the following prerequisites for inclusion: premenopausal; non-pregnant; without a diagnosis of hypothyroidism, hyperthyroidism, Cushing's syndrome, hyperandrogenism or any other type of secondary obesity; and not using medications known to interfere with cardiac autonomic modulation. Volunteers were then asked to sign an individual informed consent form, and tests were scheduled for the next possible morning. All data were collected between March 2015 and March 2017. The research protocol and the consent form were in accordance with Declaration of Helsinki as revised in 2013 and with Resolution 466/12 of the National Health Council/Brazil and approved by the Committee of Ethics in Research of UFRN (0153.0.051.000-09). 


\section{Data collection}

Participants abstained from foods and beverages containing caffeine, avoided heavy physical activity and alcohol consumption for 24 hours before tests, as recommended. All anthropometric measures [weight $(\mathrm{kg})$, height $(\mathrm{cm})$, waist circumference $(\mathrm{WC}, \mathrm{cm})$ and hip circumference $(\mathrm{HC}, \mathrm{cm})]$ were taken by one experienced examiner in accordance with guidelines proposed by the American College of Sports Medicine (ACSM 2013). Body mass index (BMI), waist-to-hip ratio (WHR) and waist-to-height ratio (WHtR) were used to determine obesity and central adiposity distribution. BMI was categorized as eutrophic (between 18.5 and $24.99 \mathrm{~kg} / \mathrm{m}^{2}$ ), overweight (between $25 \mathrm{~kg} / \mathrm{m}^{2}$ and $29.99 \mathrm{~kg}$ / $\mathrm{m}^{2}$ ) and obese (equal to or higher than $30 \mathrm{~kg} / \mathrm{m}^{2}$ ). We used $25 \mathrm{~kg} / \mathrm{m}^{2}$ and $30 \mathrm{~kg} / \mathrm{m}^{2}$ as the largely accepted cutoff points to determine the metabolic risk associated with overweight and obesity in two separate analyses (The GBD Obesity Collaborators 2017). First, we grouped all women with BMI up through $24.99 \mathrm{~kg} / \mathrm{m}^{2}$ to compare with those who had a BMI of $25 \mathrm{~kg} / \mathrm{m}^{2}$ or more; we also grouped all the women who had BMI up through $29.99 \mathrm{~kg} / \mathrm{m}^{2}$ to compare with the women with BMI of $30 \mathrm{~kg} / \mathrm{m}^{2}$ or more, in both cases to evaluate the discriminatory power of these cut-off points.

All HRV measurement recordings occurred between 08:00 and 10:00 AM to avoid circadian influences. Consecutive intervals between two $\mathrm{R}$ waves, a segment of the QRS complex that follows an upward deflection on an electrocardiogram (RR intervals), were recorded using a heart-rate monitor (RS800CX, Polar Electro OY, Kempele, Finland) (Nunan et al. 2009). After placement of chest sensors, participants laid on a comfortable mattress in a quiet room with controlled temperature and were asked to relax and breathe normally. Recordings lasted at least 10 minutes with 5 minutes of environmental acclimatization and unannounced 5-minute periods for analysis. Inter-beat intervals were extracted using Polar software Polar ProTrainer 5, 5.40.170, Polar Electro OY, Kempele, Finland (Nunan et al. 2009). Misleading signal (from movement or technical failure) detection was performed with the automated algorithm used by ARTiiFACT software, version 2.9, and processed with cubic spline interpolation as a proposed guideline (Kaufmann et al. 2011). No more than $1 \%$ of total beats needed correction. Finally, we used Kubios HRV software, version 3.0.1 (Kubios OY, Kuopio, Finland), in accordance with proposed guidelines (Tarvainen et al. 2014) to compute linear HRV measures.

\section{Data analyses}

Less than $2 \%$ of the collected data were missing and were estimated by multiple imputations, as described by Schenker and coworkers (Schenker et al. 2011). Discrepant values were identified with the outlier-labeling rule proposed by Hoaglin and Iglewicz (Hoaglin and Iglewicz 1987) and replaced by the next value not considered an outlier, as described by Dixon and Field (Dixon 1980; Field 2013). Those techniques preserve statistical test robustness for population estimations, even from small samples. Before conducting hypothesis testing, we tested the assumption of distributions normality with the Shapiro-Wilk test. The description of continuous variables included means and standard deviations.

We tested the hypothesis of differences in measures of cardiac autonomic modulation between BMI categories by analysis of variance (ANOVA). We applied the Welch robust 
test of equality of means if the assumption of homogeneity of variances were not satisfied. Fisher's least significant difference (LSD) was applied as a sequential procedure for pairwise group comparisons (Hayter 1986; Seaman, Levin, and Serlin 1991). We applied logistic regression to test if anthropometric measures could estimate the presence of cardiac autonomic dysfunction. We included variables in the model if the univariate analysis returned a $p<0.20$. In the iterative process of variable selection, covariates were removed from the model if they were non-significant and not confounders. Significance was evaluated at the 0.1 alpha level and confounding as a change in parameter estimate greater than $15 \%$ as compared to the full model. The model was then evaluated by the Hosmer-Lemeshow goodness of fit test.

Low frequency in normalized units $\left(\mathrm{LF}_{(\mathrm{nu})}\right)$ over 46 was considered a marker of autonomic imbalance and high frequency in normalized units $\left(\mathrm{HF}_{(\mathrm{nu})}\right)$ below 38 as a marker of depressed parasympathetic modulation on heart control (Billman 2013; Nunan, Sandercock, and Brodie 2010). Results were then expressed as usual test statistics, 95\% confidence intervals and standardized effect sizes estimates (eta squared, Hedges's $g$ and common language effect size) as proposed by Lakens (Lakens 2013), along with odds-ratio (OR) and prevalence ratio. Only categorical BMI (up through $24.99 \mathrm{~kg} / \mathrm{m}^{2}$ vs. $25 \mathrm{~kg} / \mathrm{m}^{2}$ and above, and up through $29,99 \mathrm{~kg} / \mathrm{m}^{2}$ vs. $30 \mathrm{~kg} / \mathrm{m}^{2}$ and above) remained in the model, and no interaction was tested in this case. All reported effect sizes remained statistically significant when evaluated with age and menstrual cycle phase as confounders.

\section{Results}

Besides great variability of linear and non-linear values as in the literature, most HRV measures fell into the expected range for the healthy female population (Nunan, Sandercock, and Brodie 2010) (Table 1). Eutrophic individuals had lower anthropometric measures and indexes of central adiposity than overweight and obese groups. Overweight individuals also scored lower than obese, as expected.

From all the anthropometric measures, only categorical BMI remained significantly related to cardiac autonomic dysfunction. Over $20 \%$ of the parasympathetic activity variance was accounted for by BMI categories. The overweight group had lower parasympathetic activity than the eutrophic group, mean difference $(\mathrm{M} \Delta)=-13.11[95 \%$ confidence interval (CI) of the difference, -25.88, -0.34], $t_{(37)}=-2.08, p=.004$, Hedges's $g=0.65$. The common language (CL) effect size estimated a $68.1 \%$ chance of parasympathetic activity in a eutrophic person to be greater than in overweight individuals, if a pair of randomly selected individuals from the general population was considered. In addition, the obese group had even lower parasympathetic activity compared to the eutrophic group $\left(\mathrm{M} \Delta=-21.22[95 \% \mathrm{CI},-31.89,-10.55], t_{(43)}=-3.94, p<.001\right.$, Hedges's $g=1.17$, CL effect size 79.2\%). An unclear difference was observed between overweight and obese groups. We further tested the hypothesis of differences below and above standard cutoff points for BMI $\left(25 \mathrm{~kg} / \mathrm{m}^{2}\right.$ and $\left.30 \mathrm{~kg} / \mathrm{m}^{2}\right)$ in an interaction model (Figure 1). Using $25 \mathrm{~kg} / \mathrm{m}^{2}$ as the threshold (overweight-obese interaction), we found $\mathrm{M} \Delta$ $=-17.17$ [95\% CI, $-26.83,-7.50], t_{(63)}=-3.30, p=.002$, Hedges's $g=0.89$, and CL effect size of $72.8 \%$; while using $30 \mathrm{~kg} / \mathrm{m}^{2}$ as the threshold (eutrophic-overweight interaction), 
Table 1. Comparison of participants' characteristics across weight groups.

\begin{tabular}{|c|c|c|c|c|c|c|}
\hline & Eutrophic (19) & Overweight (20) & Obese (26) & & & \\
\hline Variables & Mean \pm SD & Mean \pm SD & Mean \pm SD & $F$ & $p$ & $\eta^{2}$ \\
\hline Weight $(\mathrm{kg})$ & $58.00 \pm 6.92^{*}$ & $71.49 \pm 6.63^{* *}$ & $90.37 \pm 14.43^{\S}$ & $52.868^{\dagger}$ & $<.001$ & 0.632 \\
\hline Height $(\mathrm{cm})$ & $161.60 \pm 7.61$ & $160.70 \pm 6.85$ & $160.76 \pm 6.74$ & 0.103 & .903 & 0.003 \\
\hline$A C(\mathrm{~cm})$ & $79.75 \pm 6.84^{*}$ & $91.28 \pm 5.16^{* *}$ & $107.11 \pm 10.95^{\S}$ & $52.728^{\dagger}$ & $<.001$ & 0.661 \\
\hline$W C(\mathrm{~cm})$ & $71.86 \pm 5.21^{*}$ & $82.28 \pm 4.76^{* *}$ & $97.88 \pm 10.09^{\S}$ & $64.983^{\dagger}$ & $<.001$ & 0.690 \\
\hline $\mathrm{HC}(\mathrm{cm})$ & $97.48 \pm 5.68^{*}$ & $106.64 \pm 3.75^{* *}$ & $116.33 \pm 8.47^{\S}$ & $40.253^{\dagger}$ & $<.001$ & 0.599 \\
\hline BMI $(\mathrm{kg} / \mathrm{m} 2)$ & $22.17 \pm 1.83^{*}$ & $27.65 \pm 1.40^{* *}$ & $34.86 \pm 4.39^{\S}$ & $104.862^{\dagger}$ & $<.001$ & 0.758 \\
\hline WHR & $0.74 \pm 0.05$ & $0.77 \pm 0.05^{* *}$ & $0.84 \pm 0.06^{\S}$ & 20.056 & $<.001$ & 0.393 \\
\hline WHtR & $0.44 \pm 0.03^{*}$ & $0.51 \pm 0.03^{* *}$ & $0.61 \pm 0.06^{\S}$ & 78.766 & $<.001$ & 0.718 \\
\hline MeanRR (ms) & $865.91 \pm 135.91$ & $856.79 \pm 147.48$ & $802.16 \pm 105.73$ & 1.670 & .197 & 0.051 \\
\hline SDNN (ms) & $52.28 \pm 15.39$ & $53.04 \pm 19.82$ & $49.06 \pm 18.74$ & 0.316 & .730 & 0.010 \\
\hline MeanHR (bpm) & $71.16 \pm 10.66$ & $72.77 \pm 12.17$ & $76.34 \pm 10.27$ & 1.326 & .273 & 0.041 \\
\hline LF(nu) & $47.02 \pm 21.88^{*}$ & $60.08 \pm 17.48$ & $68.09 \pm 14.52^{\S}$ & 7.693 & .001 & 0.199 \\
\hline $\mathrm{HF}(\mathrm{nu})$ & $52.79 \pm 21.89^{*}$ & $39.68 \pm 17.30$ & $31.57 \pm 14.26^{\S}$ & 7.920 & .001 & 0.204 \\
\hline
\end{tabular}

$\mathrm{AC}=$ abdominal circumference; $\mathrm{bpm}=$ beats per minute; $\mathrm{HC}=$ hip circumference; $\mathrm{HF}(\mathrm{nu})=$ high frequency in normalized units; $L F(n u)=$ low frequency in normalized units; MeanRR = mean of the intervals between two $\mathrm{R}$ waves; $\mathrm{ms}=$ milliseconds; SD = standard deviation; SDNN = standard deviation of the mean of all normal intervals between two $\mathrm{R}$ waves; $\mathrm{WC}=$ waist circumference; $\mathrm{WHR}=$ waist-to-hip ratio; $\mathrm{WHtR}=$ waist-to-height ratio; $\eta^{2}=$ eta squared.

${ }^{+}$Welch's $F$

${ }^{*} p<.05$ eutrophic-overweight comparison

${ }^{* *} p<.05$ overweight-obese comparison

$\S p<.05$ eutrophic-obese comparison.
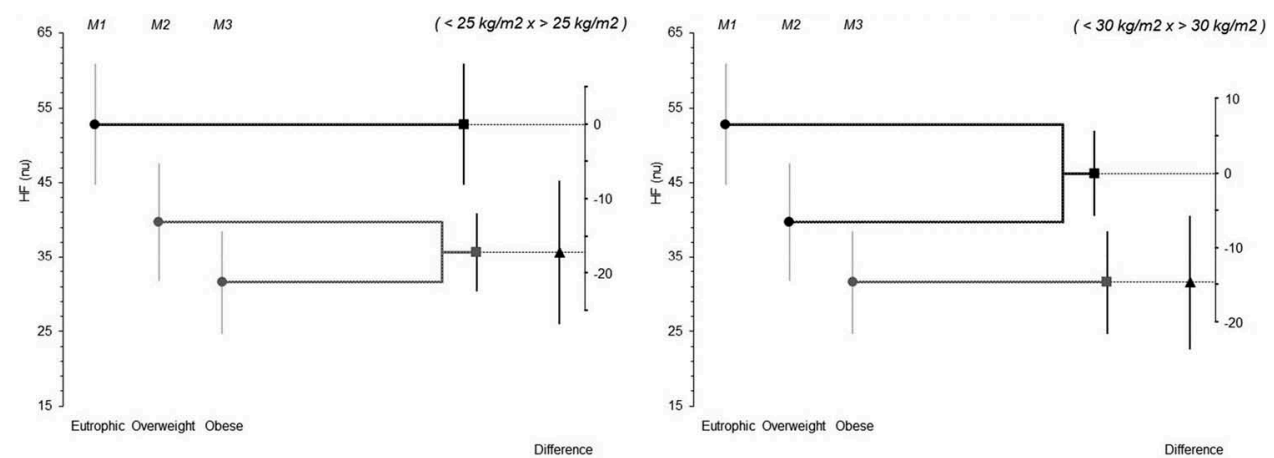

Figure 1. Parasympathetic activity above and below standard BMI cutoff points.

Point and range estimates $(95 \% \mathrm{Cl})$ for mean differences of combined effects between below and above standard BMI cutoff points. Scale in normalized units. $\mathrm{HF}(\mathrm{nu})=$ high frequency in normalized units; $M 1$ = eutrophic mean; $M 2$ = overweight mean; $M 3$ = obese mean.

we found $\mathrm{M} \Delta=-14.67$ [95\% CI, $-23.62,-5.71], t_{(63)}=-3.53, p<.001$, Hedges's $g=0.88$, and CL effect size of $74.1 \%$.

Almost $20 \%$ of the autonomic imbalance in cardiac control variance was dependent on the BMI categories. The overweight group presented greater imbalance than the eutrophic $\left(\mathrm{M} \Delta=13.06\right.$ [95\% CI, 1.65, 24.47], $t_{(37)}=-2.06, p=.046$, Hedges's $g=0.65$, and CL effect size $67.9 \%$ ) or the obese group ( $\mathrm{M} \Delta=21.07$ [95\% CI, 10.32, 31.82], $t_{(43)}=-3.88, p<.001$, Hedges's $g=1.15$, and CL effect size $\left.78.9 \%\right)$. No difference was identified between the overweight and obese groups for autonomic imbalance in cardiac control. The difference between those with BMI up through $24,99 \mathrm{~kg} / \mathrm{m}^{2}$ and those with BMI $25 \mathrm{~kg} / \mathrm{m}^{2}$ and above (eutrophic vs overweight and 

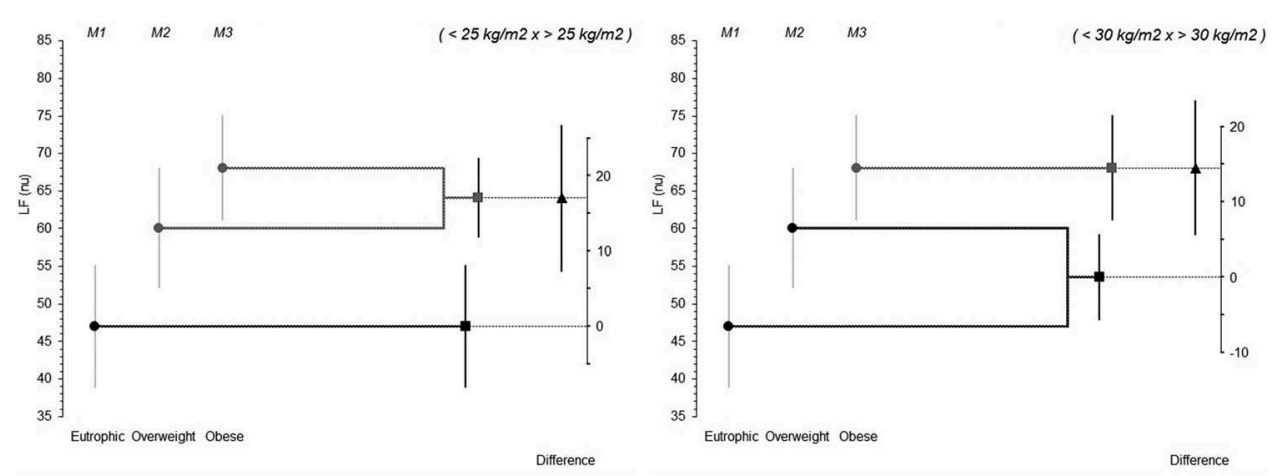

Figure 2. Autonomic imbalance above or below standard BMI cutoff points.

Point and range estimates $(95 \% \mathrm{Cl})$ for mean differences of combined effects between below and above standard BMI cutoff points. Scale in normalized units. $\operatorname{LF}(\mathrm{nu})=$ low frequency in normalized units; $M 1$ = eutrophic mean; $M 2$ = overweight mean; $M 3$ = obese mean.

obese groups combined) were $\mathrm{M} \Delta=17.07$ [95\% CI, 7.33, 26.81], $t_{(63)}=3.27$, $p=.002$, Hedges's $g=0.88$, and CL effect size $72.7 \%$; and between those with BMI through $29,99 \mathrm{~kg} / \mathrm{m}^{2}$ and those with BMI $30 \mathrm{~kg} / \mathrm{m}^{2}$ and above (eutrophic and overweight groups combined vs. obese) had $\mathrm{M} \Delta=14.54$ [95\% CI, 5.52, 23.56], $t_{(63)}=-3.47, p=.001$, Hedges's $g=0.87$, and CL effect size 73.7\% (Figure 2).

The capacity of BMI $25 \mathrm{~kg} / \mathrm{m}^{2}$ and above to identify depressed parasympathetic modulation $\left(\mathrm{HF}_{(\mathrm{nu})}\right.$ lower than 38$)$ was $56.9 \%$ with odds-ratio $(\mathrm{OR})=2.36(95 \% \mathrm{CI}$ $[0.77,7.29]$ ) and prevalence ratio of $342 \%$. When using BMI $30 \mathrm{~kg} / \mathrm{m}^{2}$ as the threshold, the model's capacity was $60 \%$, with $\mathrm{OR}=2.18(95 \% \mathrm{CI}[0.79,5.99])$ and prevalence ratio of $123 \%$. BMI $25 \mathrm{~kg} / \mathrm{m}^{2}$ and above identified autonomic imbalance on heart control $\left(\mathrm{LF}_{(\text {n.u. }}\right)$ with a predictive capacity of $78.5 \%, \mathrm{OR}=9.17(95 \% \mathrm{CI}[2.62,32.04])$ and prevalence ratio of $347 \%$, while BMI $30 \mathrm{~kg} / \mathrm{m}^{2}$ and above presented a predictive capacity of $78.5 \%, \mathrm{OR}=17.39(95 \% \mathrm{CI}[2.13,141.76])$ and prevalence ratio of $86 \%$. The analysis of goodness-of-fit held $\mathrm{X}_{(8)}^{2}=6.329, p=.610$ and $\mathrm{X}_{(8)}^{2}=7.912, p=.442$, respectively.

\section{Discussion}

Herein we have demonstrated that BMI contributes to about $20 \%$ of the variance in parasympathetic activity and in the autonomic imbalance of heart control, which in turn can lead to cardiac autonomic dysfunction. Our data suggest that this contribution occurs as soon as BMI is greater than the $25 \mathrm{~kg} / \mathrm{m}^{2}$ cutoff point, and we can imply that it stabilizes across higher BMI categories as unclear differences were observed between overweight and obese groups. Exceeding the $25 \mathrm{~kg} / \mathrm{m}^{2}$ cutoff point seems to be sufficient for this higher BMI itself to be related to cardiac autonomic dysfunctions.

The literature argues that increased imbalance in autonomic heart control coupled with decreased parasympathetic activity is associated with clinical outcomes, such as essential hypertension, congestive heart failure and atrial fibrillation (Xhyheri et al. 2012). Anthropometric measures are direct estimates of obesity and central fat distribution, and they represent reliable means to estimate its content (Direk et al. 2013; Nazare et al. 2015). Our results identified differences in nutritional level and central fat distribution 
between eutrophic, overweight and obese women (Table 1). Two major deposits of adipose tissue occur in humans, subcutaneous and visceral fat. Both are able to expand to accommodate the excess energy through the remodeling of adipose tissue. However, under pathophysiological conditions, such as progression of obesity, anomalous adipose tissue remodeling may induce dysregulation of adipose tissue-derived cytokines and hormones, leading to metabolic disorders (Choe et al. 2016; Huh et al. 2014). In particular, excessive visceral fat is closely linked to metabolic disorders, such as insulin resistance and type 2 diabetes, and risk of cardiac complications (Gesta, Tseng, and Kahn 2007; Konrad 2012). The chosen BMI cut-off points $\left(25 \mathrm{~kg} / \mathrm{m}^{2}\right.$ and $\left.30 \mathrm{~kg} / \mathrm{m}^{2}\right)$ have been exhaustively examined and are well-established indicators of increased risk of morbidity and mortality, and have discriminating power to detect cardiometabolic disturbances (The GBD Obesity Collaborators 2017).

The first widely accepted standards for interpreting and classifying HRV measures developed by the Task Force of the European Society of Cardiology and the North American Society of Pacing and Electrophysiology were published in 1996 (Malik 1996). They were systematically reviewed and updated in 2010 by other researchers (Nunan, Sandercock, and Brodie 2010). We considered, as a criterion, the presence of cardiac autonomic dysfunction when the low frequency in normalized units $\left(\operatorname{LF}_{(\mathrm{nu})}\right)$ was above 46, and the high frequency in normalized units $\left(\mathrm{HF}_{(\mathrm{nu})}\right)$ was below 38 in accordance with reviewed values (Nunan, Sandercock, and Brodie 2010). This decision increases the screening sensitivity, which is necessary to identify initial cases for further investigation in an asymptomatic population. The objective is to reduce morbidity or mortality among women who are obese by early detection of imbalances in the autonomic control of the heart, when treatment may be more successful (Maxim, Niebo, and Utell 2014).

Parasympathetic activity as assessed by $\mathrm{HF}_{(\mathrm{nu})}$ differed between $\mathrm{BMI}$ categories. $\mathrm{HF}_{(\mathrm{nu})}$ is an HRV measure that represents at least $90 \%$ of the vagal influence on heart control (Billman 2013). Therefore, lower values of $\mathrm{HF}_{(\mathrm{nu})}$ represent a reduction in vagal activity in the heart. The associations between $\mathrm{HF}_{(\mathrm{nu})}$ and obesity have been previously evaluated through cross-sectional and longitudinal studies. Previous authors have identified decreased parasympathetic activity over BMI $25 \mathrm{~kg} / \mathrm{m}^{2}$ in accordance with our findings (Koenig et al. 2014). In another study, the same authors investigated a large sample, focusing on identifying associations between anthropometric measures of adiposity and autonomic nervous system function (Koenig et al. 2015). Although they only found weak coefficients of correlation, their results agree with our conclusions. Previous longitudinal studies provided additional support for this association because the increase in vagal activity occurs after weight loss and remains higher during the maintenance period (Laaksonen et al. 2003; Rissanen, Franssila-Kallunki, and Rissanen 2001).

The use of $\mathrm{LF}_{(\mathrm{nu})}$ as a direct measure of sympathetic activation and reduced vagal influence on the heart is controversial. Billman summarized the scientific literature, reporting that such an interpretation of $\mathrm{LF}_{(\mathrm{nu})}$ is misleading (Billman 2013) and suggesting that $\mathrm{LF}_{(\mathrm{nu})}$ is a complex combination of sympathetic and parasympathetic activity, in addition to other still unidentified factors. However, most published scientific reports consider $\mathrm{LF}_{(\mathrm{nu})}$ as a direct measure of sympathetic modulation on the heart. We considered positive fluctuations of $\mathrm{LF}_{(\mathrm{nu})}$ as a measure of autonomic imbalance of heart control without assuming any final concept. In the present report, $\mathrm{LF}_{(\mathrm{nu})}$ was increased in women who were overweight and obese, and the chance of prevalence of cardiac 
autonomic dysfunction among these populations was more than twice that among eutrophic individuals. This finding is consistent with those from recent longitudinal and cross-sectional studies.

Kubera and coworkers evaluated the evolution of body form through time related to stress (Kubera et al. 2017). The authors reported that an increase in BMI was associated with an increase in HRV imbalance in men, but only an associated trend in women. One of the reasons pointed out by the authors was the sample size of females. As women are often under-represented in the cardiovascular research literature, our study contributes to the knowledge base regarding this population. Another study conducted by Rosato and collaborators found moderate positive correlations between low frequency and BMI (Rosato et al. 2017). However, these findings are not consistent with other previous research (Koenig et al. 2014).

It is important to emphasize that such imbalance has been widely linked with cardiovascular disease related to overweight and obesity (Feldstein and Julius 2009). It involves upraised recruitment of previously silent efferent sympathetic nerve fibers firing at a normal rate as one increases adipose fat deposits (Lambert et al. 2007). Moreover, obesityrelated hyperinsulinemia directly stimulates the sympathetic nervous system through the hypothalamic activation or indirectly through baroreflex activation. This phenomenon is mediated by insulin-associated vasodilation through negative feedback, as an innocuous attempt to increase energy expenditure to avoid body fat accumulation (Alrefaie 2014).

Even though our data did not support the concept that fat distribution correlated with variation in HRV measures, not only the amount but also the localization of adipose tissue can influence cardiac autonomic modulation. Central accumulation of adipose tissue correlates with autonomic imbalances in heart control with a similar pattern as anthropometric measures (Direk et al. 2013). Visceral fat, as an endocrine organ, is capable of releasing several pro-inflammatory cytokines, which interact with the autonomic nervous system. Such imbalances are associated with increased pro-inflammatory cytokine production (Adam et al. 2017) and can affect systemic processes such as immunity (Czura and Tracey 2005). Those biomarkers of systemic inflammation are well-established influencers of metabolic and cardiac complications such as insulin resistance and atherosclerosis. In contrast, increased parasympathetic activity and acetylcholine release attenuate such cytokine production (Sturmberg et al. 2015). Therefore, autonomic imbalances in heart control can be reversed by modifications in body composition through fat reduction, primarily as visceral deposits.

As mentioned earlier, excessive sympathetic activation has a deleterious effect on the human body, and its relationship with sedentary behavior, aging and body composition appear as an important topic of discussion in the literature, and although our findings improve knowledge on this topic, some limitations are evident. Heart rate regulation does not solely depend on autonomic nervous system control (Besnier et al. 2017). However, to what extent each of them influences cardiac autonomic modulation is still not fully established, especially when physical conditioning is taken into account. Consequently, factors such as genetics, intrinsic adaptations of the sinus node, increased venous return and systolic volume, improvement in cardiac muscle contractility and oxygen use may influence autonomic heart control causing divergences and controversies when analyzing different populations. The way cardiac autonomic modulation is measured is also the 
cause of controversies, since the results obtained at rest may not fully characterize the cardiovascular system and its regulatory mechanisms (Tulppo et al. 1998).

In addition, our cross-sectional design did not allow us to assess the temporal and, thus, potentially causal relationships of the variables. Further, the relatively small sample size might have resulted in inadequate statistical power to detect modest but meaningful associations as statistically significant. Finally, the non-representative nature of the sample might have limited the generalizability of our findings. However, we might suggest that the same associations would be present in a male population.

In addition to addressing the above limitations, we also suggest that future studies investigate the biochemical and neurohormonal pathways as possible mechanisms of action that might explain the interactions evidenced herein. Primarily, it is fundamental to indicate the starting point in this circular biofeedback interaction among inflammation, immune system, metabolism, and autonomic heart control.

In conclusion, parasympathetic activity lowers and autonomic imbalance of cardiac control increases across increasing BMI categories. Our results indicate the capacity for early clinical assessment of these autonomic imbalances. BMI has the potential to identify asymptomatic cardiac disorders related to depressed parasympathetic activity whenever it is necessary to increase the sensitivity of screening, especially in an apparently healthy female population with metabolic risk, or when more accurate tests are not available.

\section{Disclosure}

All authors declared no conflict of interest.

\section{References}

ACSM. 2013. ACSM's guidelines for exercise testing and prescription. Philadelphia, PA: Lippincott Williams \& Wilkins.

Adam, M., M. Imboden, E. Schaffner, E. Boes, F. Kronenberg, M. Pons, R. Bettschart, J.C. Barthelemy, C. Schindler, and N. Probst-Hensch. 2017. The adverse impact of obesity on heart rate variability is modified by a NFE2L2 gene variant: The SAPALDIA cohort. International Journal of Cardiology 228:341-46. doi:10.1016/j.ijcard.2016.11.049.

Alrefaie, Z. 2014. Brief assessment of supine heart rate variability in normal weight, overweight, and obese females. Annals of Noninvasive Electrocardiology 19 (3):241-46. doi:10.1111/anec.12120.

Besnier, F., M. Labrunee, A. Pathak, A. Pavy-Le Traon, C. Gales, J. M. Senard, and T. Guiraud. 2017. Exercise training-induced modification in autonomic nervous system: An update for cardiac patients. Annals of Physical and Rehabilitation Medicine 60 (1):27-35. doi:10.1016/j. rehab.2016.07.002.

Billman, G. E. 2013. The LF/HF ratio does not accurately measure cardiac sympatho-vagal balance. Frontiers in Physiology 4:26. doi:10.3389/fphys.2013.00026.

Chang, V. W., D. E. Alley, and J. B. Dowd. 2017. Trends in the relationship between obesity and disability, 1988-2012. American Journal of Epidemiology 186 (6):688-95. doi:10.1093/aje/kwx092.

Choe, S. S., J. Y. Huh, I. J. Hwang, J. I. Kim, and J. B. Kim. 2016. Adipose tissue remodeling: Its role in energy metabolism and metabolic disorders. Frontiers in Endocrinology 7. doi:10.3389/ fendo.2016.00089.

Czura, C. J., and K. J. Tracey. 2005. Autonomic neural regulation of immunity. Journal of Internal Medicine 257 (2):156-66. doi:10.1111/j.1365-2796.2004.01442.x.

Daniel, M. L., R. Niebo, and M. J. Utell. 2014. Screening tests: A review with examples. Inhalation Toxicology 26 (13):811-28. doi:10.3109/08958378.2014.955932. 
Direk, K., M. Cecelja, W. Astle, P. Chowienczyk, T. D. Spector, M. Falchi, and T. Andrew. 2013. The relationship between DXA-based and anthropometric measures of visceral fat and morbidity in women. BMC Cardiovascular Disorders 13 (1):25. doi:10.1186/1471-2261-13-31.

Dixon, W. J. 1980. Efficient analysis of experimental observations. Annual Review of Pharmacology and Toxicology 20:441-62. doi:10.1146/annurev.pa.20.040180.002301.

Faul, F., E. Erdfelder, A. Buchner, and A. G. Lang. 2009. Statistical power analyses using G*Power 3.1: Tests for correlation and regression analyses. Behavior Research Methods 41 (4):1149-60. doi:10.3758/BRM.41.4.1149.

Feldstein, C., and S. Julius. 2009. The complex interaction between overweight, hypertension, and sympathetic overactivity. Journal of the American Society of Hypertension 3 (6):353-65. doi:10.1016/j.jash.2009.10.001.

Field, A. S. 2013. Discovering statistics using IBM SPSS statistics. 4th ed. Oaks, CA: Sage Publications.

Gesta, S., Y.-H. Tseng, and C. Ronald Kahn. 2007. Developmental origin of fat: Tracking obesity to its source. Cell 131 (2):242-56. doi:10.1016/j.cell.2007.10.004.

Hayter, A. J. 1986. The maximum familywise error rate of Fisher's least significant difference test. Journal of the American Statistical Association 81 (396):1000-04. doi:10.1080/ 01621459.1986.10478364.

Hoaglin, D. C., and B. Iglewicz. 1987. Fine-tuning some resistant rules for outlier labeling. Journal of the American Statistical Association 82 (400):1147-49. doi:10.1080/ 01621459.1987.10478551.

Huh, J. Y., Y. J. Park, M. Ham, and J. B. Kim. 2014. Crosstalk between adipocytes and immune cells in adipose tissue inflammation and metabolic dysregulation in obesity. Molecules and Cells 37 (5):365-71. doi:10.14348/molcells.2014.0074.

Kaufmann, T., S. Sutterlin, S. M. Schulz, and C. Vogele. 2011. ARTiiFACT: A tool for heart rate artifact processing and heart rate variability analysis. Behavior Research Methods 43 (4):1161-70. doi:10.3758/s13428-011-0107-7.

Koenig, J., B. G. Windham, L. Ferrucci, D. Sonntag, J. E. Fischer, J. F. Thayer, and M. N. Jarczok. 2015. Association strength of three adiposity measures with autonomic nervous system function in apparently healthy employees. The Journal of Nutrition, Health \& Aging 19 (9):879-82. doi:10.1007/s12603-015-0508-x.

Koenig, J., M. N. Jarczok, M. Warth, R. J. Ellis, C. Bach, T. K. Hillecke, and J. F. Thayer. 2014. Body mass index is related to autonomic nervous system activity as measured by heart rate variabilityA replication using short term measurements. The Journal of Nutrition, Health \& Aging 18 (3):300-02. doi:10.1007/s12603-014-0022-6.

Konrad, D. 2012. Visceral fat and metabolic inflammation: The portal theory revisited. Obesity Reviews 13 (S2):30-39. doi:10.1111/j.1467-789X.2012.01035.x.

Kubera, B., C. Leonhard, A. Rößler, and A. Peters. 2017. Stress-related changes in body form: Results from the whitehall II study. Obesity (Silver Spring, Md.) 25 (9):1625-32. doi:10.1002/ oby. 21928.

Laaksonen, D. E., T. Laitinen, J. Schönberg, A. Rissanen, and L. K. Niskanen. 2003. Weight loss and weight maintenance, ambulatory blood pressure and cardiac autonomic tone in obese persons with the metabolic syndrome. Journal of Hypertension 21 (2):371-78. doi:10.1097/01. hjh.0000052440.12292.f9.

Lakens, D. 2013. Calculating and reporting effect sizes to facilitate cumulative science: A practical primer for t-tests and ANOVAs. Frontiers in Psychology 4:863. doi:10.3389/fpsyg.2013.00186.

Lambert, E., N. Straznicky, M. Schlaich, M. Esler, T. Dawood, E. Hotchkin, and G. Lambert. 2007. Differing pattern of sympathoexcitation in normal-weight and obesity-related hypertension. Hypertension 50 (5):862-68. doi:10.1161/HYPERTENSIONAHA.107.094649.

Lee, B. Y., S. M. Bartsch, L. A. Yeeli Mui, M. L. S. Haidari, and J. Gittelsohn. 2017. A systems approach to obesity. Nutrition Reviews 75 (suppl_1):94-106. doi:10.1093/nutrit/nuw049.

Malik, M. 1996. Task force of the European society of cardiology and the north American society of pacing and electrophysiology. Heart rate variability. Standards of measurement, physiological interpretation, and clinical use. European Heart Journal 17:354-81. 
Nazare, J.-A., J. Smith, A.-L. Borel, P. Aschner, P. Barter, L. Van Gaal, C. E. Tan, H.-U. Wittchen, Y. Matsuzawa, and T. Kadowaki. 2015. Usefulness of measuring both body mass index and waist circumference for the estimation of visceral adiposity and related cardiometabolic risk profile (from the INSPIRE ME IAA study). The American Journal of Cardiology 115 (3):307-15. doi:10.1016/j.amjcard.2014.10.039.

Nishida, C., G. T. Ko, and S. Kumanyika. 2010. Body fat distribution and noncommunicable diseases in populations: Overview of the 2008 WHO expert consultation on waist circumference and waist-hip ratio. European Journal of Clinical Nutrition 64 (1):2-5. doi:10.1038/ejcn.2009.139.

Nunan, D., G. Donovan, D. G. Jakovljevic, L. D. Hodges, G. R. Sandercock, and D. A. Brodie. 2009. Validity and reliability of short-term heart-rate variability from the Polar S810. Medicine and Science in Sports and Exercise 41 (1):243-50. doi:10.1249/MSS.0b013e318184a4b1.

Nunan, D., G. R. H. Sandercock, and D. A. Brodie. 2010. A quantitative systematic review of normal values for short-term heart rate variability in healthy adults. Pacing and Clinical Electrophysiology 33 (11):1407-17. doi:10.1111/j.1540-8159.2010.02841.x.

Rissanen, P., A. F. Kallunki, and A. Rissanen. 2001. Cardiac parasympathetic activity is increased by weight loss in healthy obese women. Obesity Research 9 (10):637-43. doi:10.1038/oby.2001.84.

Rosato, E., A. Gigante, M. Liberatori, M. L. Gasperini, B. Barbano, A. Amoroso, L. Tubani, and A. Laviano. 2017. Altered diurnal cardiac sympathovagal balance correlates with nutritional status indexes in systemic sclerosis patients. Journal of Biological Regulators and Homeostatic Agents 31 (4):1133-38.

Schenker, N., L. G. Borrud, V. L. Burt, L. R. Curtin, K. M. Flegal, J. Hughes, C. L. Johnson, A. C. Looker, and L. Mirel. 2011. Multiple imputation of missing dual-energy X-ray absorptiometry data in the national health and nutrition examination survey. Statistics in Medicine 30 (3):260-76. doi:10.1002/sim.4080.

Seaman, M. A., J. R. Levin, and R. C. Serlin. 1991. New developments in pairwise multiple comparisons: Some powerful and practicable procedures. Psychological Bulletin 110 (3):577. doi:10.1037/0033-2909.110.3.577.

Sturmberg, J. P., J. M. Bennett, M. Picard, and A. J. E. Seely. 2015. The trajectory of life. Decreasing physiological network complexity through changing fractal patterns. Frontiers in Physiology 6. doi:10.3389/fphys.2015.00098.

Tarvainen, M. P., J. P. Niskanen, J. A. Lipponen, P. O. Ranta-Aho, and P. A. Karjalainen. 2014. Kubios HRV-Heart rate variability analysis software. Computer Methods and Programs in Biomedicine 113 (1):210-20. doi:10.1016/j.cmpb.2013.07.024.

The GBD Obesity Collaborators. 2017. Health effects of overweight and obesity in 195 countries over 25 years. New England Journal of Medicine 377 (1):13-27. doi:10.1056/NEJMoa1614362.

Tulppo, M. P., T. H. Mäkikallio, T. Seppänen, R. T. Laukkanen, and H. V. Huikuri. 1998. Vagal modulation of heart rate during exercise: Effects of age and physical fitness. American Journal Of Physiology-Heart And Circulatory Physiology 274 (2):H424-H429. doi:10.1152/ ajpheart.1998.274.2.H424.

Wheat, A. L., and K. T. Larkin. 2010. Biofeedback of heart rate variability and related physiology: A critical review. Applied Psychophysiology and Biofeedback 35 (3):229-42. doi:10.1007/s10484010-9133-y.

Xhyheri, B., O. Manfrini, M. Mazzolini, C. Pizzi, and R. Bugiardini. 2012. Heart rate variability today. Progress in Cardiovascular Diseases 55 (3):321-31. doi:10.1016/j.pcad.2012.09.001.

Yoo, H. J., S. Y. Hwang, K. M. Choi, S. H. Baik, E. M. Lee, E. J. Kim, S. W. Rha, C. G. Park, D. J. Oh, and H. S. Seo. 2016. Clinical implication of body size phenotype on heart rate variability. Metabolism 65 (11):1589-96. doi:10.1016/j.metabol.2016.08.002. 